\title{
Correction to: Development and Validation of Perceived Self-Transformation Scale for the Satir Model
}

\author{
Pamela Pui-Yu Leung ${ }^{1,2} \cdot$ Way Kwok-Wai Lau ${ }^{3}$ (1) $\cdot$ Catherine Lai-Ping Chung ${ }^{1}$
}

Published online: 3 December 2021

(c) Springer Science+Business Media, LLC, part of Springer Nature 2021

\section{Correction to: Contemporary Family Therapy (2019) 41:56-67 https://doi.org/10.1007/s10591-018-9477-7}

The original version of this article unfortunately contained a vague sentence in Factor Analysis subsection under Phase 1 -Results and Discussion section.

The sentence "and the reverse coded others-oriented subscale, for which the higher scores reflect lower levels of others-oriented." need to be included for better understanding.

Thus, the complete sentence should read as follows.

The higher the scores, the greater the perceived presence of the characteristics in the total and subscales of the PSTS17, except for the reverse coded self-doubt subscale, for which higher scores reflect lower levels of self-doubt, and the reverse coded others-oriented subscale, for which the higher scores reflect lower levels of others-oriented.

The original article has been corrected.

Publisher's Note Springer Nature remains neutral with regard to jurisdictional claims in published maps and institutional affiliations.
Pamela Pui-Yu Leung and Way Kwok-Wai Lau have contributed equally to this work.

The original article can be found online at https://doi.org/10.1007/ s10591-018-9477-7.

Way Kwok-Wai Lau

waylau@eduhk.hk

1 Department of Social Work and Social Administration, The University of Hong Kong, Hong Kong, China

2 The Hong Kong Society for Rehabilitation, Hong Kong, China

3 Department of Special Education and Counselling, The Education University of Hong Kong, Room 11, 2/Floor, Block D2, 10 Lo Ping Road, Tai Po, Hong Kong, China 